\title{
Anomalous codeposition of cobalt and ruthenium from chloride- sulfate baths
}

\author{
Marjaneh Jafari Fesharaki ${ }^{\mathrm{a}, \mathrm{b}}$, Gholam Reza Nabiyouni ${ }^{\mathrm{b}}$, Júlia Dégi ${ }^{\mathrm{a}}$, Lajos Pogány ${ }^{\mathrm{a}}$, \\ Ádám Révész ${ }^{\mathrm{c}}$, Imre Bakonyi ${ }^{\mathrm{a}}$, László Péter ${ }^{\mathrm{a}^{*}}$
}

a, Research Institute for Solid State Physics and Optics, Hungarian Academy of Sciences, 1525 Budapest, P.O.Box 49, Hungary

b, Department of Physics, Faculty of Science, University of Arak, Arak 38156-8-8349, Iran c, Department of Materials Physics, Eötvös University, P.O. Box 32, H-1518 Budapest, Hungary

Abstract - Codeposition of Ru and Co was studied at room temperature and at $50^{\circ} \mathrm{C}$ with various $\mathrm{Ru}^{3+}$ and $\mathrm{Co}^{2+}$ concentrations in the electrolyte. The codeposition of Co and $\mathrm{Ru}$ proved to be anomalous since no pure $\mathrm{Ru}$ could be obtained in the presence of $\mathrm{Co}^{2+}$ in the electrolyte, but a significant Co incorporation into the deposit was detected at potentials where the deposition of pure Co was not possible. The composition of the deposits varied monotonously with the change of the concentration ratio of $\mathrm{Co}^{2+}$ and $\mathrm{Ru}^{3+}$. The deposition of $\mathrm{Ru}$ was much hindered and the current efficiency was a few percent only when the molar fraction of Co in the deposit was low. Continuous deposits could be obtained only when the molar fraction of Co in the deposit was at least 40 at.\%. The deposit morphology was related to the molar fraction of Co in the deposit. The X-ray diffractograms are in conformity with a hexagonal close-packed alloy and indicate the formation of nanocrystalline deposits. Two-pulse plating did not lead to a multilayer but to a Corich alloy. Magnetoresistance of the samples decreased with increasing Ru content.

Keywords: ruthenium; cobalt; anomalous codeposition; alloy formation; pulse plating

\footnotetext{
* Corresponding author. E-mail: 1peter@szfki.hu; phone: +361-3922-2222, ext.3614; fax: +361-392-2215.
} 


\section{Introduction}

Electrodeposition of magnetic alloys containing platinum metals is in the forefront of research. While homogeneous alloys are a candidate for perpendicular magnetic recording media, the modulated structures are important because of their magnetotransport properties. The deposition of Co-Pt alloys is fairly well explored [1-6], but the literature information on the codeposition of Co with $\mathrm{Ru}$ is rather scarce.

The standard electrode potential of the $\mathrm{Ru}^{3+} / \mathrm{Ru}^{2+}$ system is as high as $0.25 \mathrm{~V}$, while that of the $\mathrm{Ru}^{2+} / \mathrm{Ru}$ system is $0.455 \mathrm{~V}$ [7]. Therefore, $\mathrm{Ru}$ can be taken as a much more noble metal than Co, but the reduction of the $\mathrm{Ru}^{3+}$ ion is much hindered, similarly to the reduction of $\mathrm{Pt}^{2+}$ ions [8]. Electrodeposition of pure $\mathrm{Ru}$ has been seldom reported in the scientific literature. Early works on the properties of electrodeposited Ru were summarized by Safranek [9]. In the literature cited therein, deposit properties having relevance in plating technology were summarized, but the electrochemical background of the deposition process was not discussed. Electrodeposition of Ru from a large variety of compounds, including $\mathrm{Ru}(\mathrm{III})$ and $\mathrm{Ru}(\mathrm{IV})$ species, was studied by Reid and Blake [10]. They found that high temperature was needed to achieve the desired deposit properties and that the current efficiency was mostly below $20 \%$.

Electrodeposition of Ru on Pt was studied by Szabó and Bakos [11]. They found that the formation of $\mathrm{Ru}$ atoms was preceded or even catalyzed by the adsorbed hydrogen atoms. At potentials where the adsorption of hydrogen atoms was not possible, the discharge of the $\mathrm{Ru}^{3+}$ ions was not complete, and the adsorbed layer could be oxidized very easily, leading to various insoluble oxides. The same experience was obtained with a quartz crystal microbalance study of electrodeposited ruthenium [12].

The electrolyte compositions [13-16] suggested in earlier studies for the electrodeposition of $\mathrm{Co}-\mathrm{Ru}$ alloys and multilayers were all based on the principle that the salt of the more noble metal has to be used in a low concentration, while that of the less noble metal can be applied in a high concentration, even close to the solubility. A similar electrolyte formulation was described for a FeCoRu bath [7]. The Ru compound used was either $\mathrm{RuCl}_{3}[7,15,16]$ or $\mathrm{Ru}(\mathrm{OH}) \mathrm{Cl}_{3}[13,14]$ and the electrolyte was very acidic in each case. The polarization behaviour of the Co-Ru system was published only for the bath containing $\mathrm{Ru}^{4+}, \mathrm{Co}^{2+}$, sulfuric acid and sulfamic acid at $60{ }^{\circ} \mathrm{C}$, and the $c\left(\mathrm{Co}^{2+}\right) / c\left(\mathrm{Ru}^{4+}\right)$ concentration ratio in the electrolyte was a fixed value of 18.75 [13]. Compositionally modulated deposits were also produced in the Co- $\mathrm{Ru}$ system. The formation of alternating Co-rich and $\mathrm{Ru}$-rich layers with a thickness of several hundred nanometers was verified by a glow discharge optical spectroscopic depth profile analysis [14]. The alloyed nature 
of both types of layer could be clearly seen from the composition depth profile functions. The formation of nanoscale multilayer deposits was also confirmed by transmission electron microscopy [16], although the composition of the Ru-rich layer was not established in the latter case.

The aim of this work was to investigate the codeposition characteristics in the Co-Ru system with various concentration ratios of the metal salts at room temperature $\left(23^{\circ} \mathrm{C}\right)$ and at high temperature $\left(50{ }^{\circ} \mathrm{C}\right)$. It was of special importance to clarify whether $\mathrm{Co}-\mathrm{Ru} / \mathrm{Ru}$ type multilayers with a pure Ru spacer between the magnetic layers can be deposited. The latter feature is a crucial factor in achieving giant magnetoresistance (GMR) in magnetic/non-magnetic multilayers, especially in the $\mathrm{Co} / \mathrm{Ru}$ system where the largest coupling strength was measured [17]. The GMR achieved was about $0.1 \%$ only in $\mathrm{Co} / \mathrm{Ru}$ multilayers prepared by either physical [18-20] or electrochemical [16] methods. Regardless of the preparation technique of the $\mathrm{Co} / \mathrm{Ru}$ sandwich structures, a significant intermixing of the layers was observed [20], which can be attributed to the complete miscibility of Co and $\mathrm{Ru}$ in a hexagonal phase [21]. It is of particular interest whether the relatively low preparation temperature during electrodeposition may help to prevent the intermixing of $\mathrm{Co}$ and $\mathrm{Ru}$.

\section{Experimental}

Analytical grade chemicals were used to prepare all electrolyte solutions. $\mathrm{CoSO}_{4} \cdot 7 \mathrm{H}_{2} \mathrm{O}, \mathrm{H}_{3} \mathrm{BO}_{3}$, $\mathrm{KCl}$ and $\mathrm{MgSO}_{4}$ were obtained from Reanal (Hungary). $\mathrm{RuCl}_{3}$ was purchased from Aldrich. All solutions were prepared with $18 \mathrm{M} \Omega \mathrm{cm}$ ultrapure water. The composition of the solutions is summarized in Table $1 . \mathrm{KCl}$ was added to ensure that $\mathrm{Ru}^{3+}$ is dominantly complexed by the chloride ions (complex formation with $\mathrm{Co}^{2+}$ is not significant). Electrolyte 1 is analogous to many baths used for the deposition of magnetic/non-magnetic multilayers in the sense that it contains the salt of the magnetic metal in a high concentration and the salt of the non-magnetic, more noble metal in a low concentration. In the rest of the solutions, $\mathrm{MgSO}_{4}$ partly replaces $\mathrm{CoSO}_{4}$ in order to keep the ionic strength constant and to enable one to compare the results. Boric acid was used to stabilize the $\mathrm{pH}$ of the electrolytes when hydrogen evolution occurred. The speciation of the Ru chloride-sulfate solutions is very complicated, as shown by Zhu et al. [22]. The observed time-dependence of the $\mathrm{Ru}^{3+}$ speciation [22] was excluded by the application of aged electrolytes only.

The working electrode was either a polycrystalline $\mathrm{Cu}$ sheet or a wafer coated by evaporation with a $\mathrm{Cr}$ adhesive and a $\mathrm{Cu}$ seed layer $[\mathrm{Si} / \mathrm{Cr}(5 \mathrm{~nm}) / \mathrm{Cu}(20 \mathrm{~nm})]$. The exposed surface area of the 
working electrode was typically $1.5 \mathrm{~cm}^{2}$. A saturated calomel electrode (SCE) was connected to the main compartment of the cell with a Luggin capillary. The reference electrode vessel was filled up with a Ru-free electrolyte with otherwise the same composition as the actual test solution in order to exclude the damage of the calomel electrode due to the $\mathrm{Ru}^{3+}$ reduction. The counter electrode was a Pt ribbon. An Elektroflex potentiostat/galvanostat was used as a power source for both d.c. deposition and pulse-plating experiments.

The composition analysis of the deposits was performed with a RÖNTEC electron probe microanalysis facility of a JEOL 840 type scanning electron microscope. No charging effect was observed during either the imaging or the analysis; therefore, all samples proved to be metallic with no significant portion of non-metallic inclusion. Composition data shown were obtained as the average of 4 to 6 measurements on different spots of at least $200 \mu \mathrm{m} \times 300 \mu \mathrm{m}$ surface area. The typical scatter of the data was 2 and $5 \%$ where the composition changes slowly and fast with the current density, respectively. The accuracy of the determination of the Co to Ru ratio was about 1 at.\%. The oxygen content of the deposits was at most a few percent for samples with high $\mathrm{Ru}$ content and it decreased significantly when the Co content of the samples was high. A Philips equipment with $\mathrm{Cu} \mathrm{K \alpha}$ radiation (wavelength: $0.15406 \mathrm{~nm}$ ) was used to carry out X-ray diffraction (XRD) measurements for the deposits. Magnetoresistance measurements were performed in the four-point-in-line geometry at room temperature up to $\pm 8 \mathrm{kOe}$ in both longitudinal and transverse modes.

\section{Results and discussion}

\subsection{Experiments with electrolytes of high $\mathrm{Co}^{2+}$ content (Electrolyte 1)}

Figure 1 shows the cyclic voltammetric curves obtained for Electrolyte 1. The figure presents two additional potentiodynamic curves for comparison: one measurement performed with a $\mathrm{Ru}$-free electrolyte of otherwise identical composition and another one obtained with a Co-free electrolyte where $\mathrm{MgSO}_{4}$ replaced $\mathrm{CoSO}_{4}$ in order to keep the ionic strength constant. When $\mathrm{Ru}$ is not present in the bath, the onset of the Co deposition potential can be established as $-0.73 \mathrm{~V}$. Therefore, in the case of normal codeposition, no Co deposition would be expected to occur at potentials more positive than $-0.73 \mathrm{~V}$. The increase in the cathodic current for the Ru bath starts at $-0.44 \mathrm{~V}$, according to both the cathodic-going and anodic-going sweeps obtained for the Cofree electrolyte. However, no deposit is formed until the potential reaches about $-0.5 \mathrm{~V}$, and a large part of the current can be attributed to either the evolution of hydrogen or the formation of 
$\mathrm{Ru}^{2+}$ ions. When both $\mathrm{Co}^{2+}$ and $\mathrm{Ru}^{3+}$ ions are present in the bath, however, the onset of deposition can be seen at $-0.39 \mathrm{~V}$, which is more positive than the deposition potentials obtained for baths in which one sort of electroactive ion was present only. The observed current accounts for the side reactions until about $-0.5 \mathrm{~V}$, similarly to the $\mathrm{Ru}$ bath.

It also has to be noticed that the curve recorded for Electrolyte 1 cannot be obtained as the sum of the curves recorded for the baths with one type of metal cation. The dissolution of Co starts at $0.49 \mathrm{~V}$, while the dissolution of pure $\mathrm{Ru}$ does not take place in the potential interval studied. The dissolution of the deposit obtained from Electrolyte 1 starts at $-0.4 \mathrm{~V}$. However, the comparison of the cathodic and anodic charge passed during the sweeps and the amount of deposits obtained indicate that the deposition efficiency is very low, similarly to the data published for the Ru baths with no alloying element [10].

The chemical analysis of the product of metal ion reduction was possible only when the deposition rate was large enough to obtain a fairly continuous deposit. Small crystals were obtained only between -0.45 and $-0.6 \mathrm{~V}$ that all contained Co besides $\mathrm{Ru}$. Continuous deposit was obtained at potentials more negative than $-0.6 \mathrm{~V}$. At $-0.625 \mathrm{~V}$, the Co content of the deposit was already 66 at.\% and it reached 90 at.\% at $-0.7 \mathrm{~V}$. At more negative potentials (or larger cathodic current densities), the Co content increased monotonously with the cathodic polarization, and the Ru content was reduced down to below the detection limit at $j=-30 \mathrm{mAcm}^{-2}$. The results of the chemical analysis showed that the Co-Ru codeposition process is anomalous since Co is deposited as an alloy component at more positive potentials than from the Ru-free bath. Therefore, deposition of a pure Ru layer cannot be expected from Electrolyte 1. The anomalous nature of the codeposition of $\mathrm{Co}$ and $\mathrm{Ru}$ prevents the formation of $\mathrm{Co}-\mathrm{Ru} / \mathrm{Ru}$ type multilayers. This is the reason why the composition depth profile measurement performed for Co$\mathrm{Ru}$ samples deposited from solutions of high $\mathrm{Co} / \mathrm{Ru}$ concentration ratio showed a significant $\mathrm{Co}$ content in the layer obtained from the low-current pulse [14].

\subsection{Variation of the $\mathrm{Co}^{2+}$ to $\mathrm{Ru}^{3+}$ concentration ratio (Electrolytes 2-5)}

Figure 2.a shows the cyclic voltammograms recorded for Solutions 2 to 5 in the low current density range. For $c\left(\mathrm{Co}^{2+}\right) / c\left(\mathrm{Ru}^{3+}\right) \leq 4$ (Solutions 3 to 5$)$, the current density decreases as the $\mathrm{Ru}^{3+}$ concentration increases. This trend is just the opposite what one could expect from the results obtained for Solution 1 where the addition of $\mathrm{Ru}^{3+}$ increased the cathodic current density. These results clearly show the complexity of the electrochemical behaviour of the Co-Ru system. It is important to note that the current increase in the low overpotential region cannot be the 
impact of solely the $\mathrm{Ru}^{3+}$ ions but it was caused by the simultaneous presence of both $\mathrm{Ru}^{3+}$ and $\mathrm{Co}^{2+}$. The synergetic effect of the $\mathrm{Ru}^{3+}$ and $\mathrm{Co}^{2+}$ ions is also shown by the polarization data of Solution 2 where the $\mathrm{Ru}^{3+}$ concentration is too low to lead to any deposition in the low-current region.

For Solution 2 where $c\left(\mathrm{Co}^{2+}\right) / c\left(\mathrm{Ru}^{3+}\right)=20$, the current density remains very small in the potential region where the Co deposition is not possible. The peak centered at $-0.6 \mathrm{~V}$ exhibits a much smaller current than the same peak in the voltammograms of the solutions with the same overall metal ion concentration but with smaller $\mathrm{Co}^{2+}$ to $\mathrm{Ru}^{3+}$ concentration ratio.

The comparison of the polarization curves obtained for Electrolytes 1 (Fig. 1) and 3 (Fig. 2) deserves particular attention because they exhibit the same $\mathrm{Ru}^{3+}$ content with varying $\mathrm{Co}^{2+}$ concentration. The current at $1 \mathrm{~mol} /$ liter $\mathrm{Co}^{2+}$ concentration is about half of the current for the electrolyte with $0.1 \mathrm{~mol} /$ liter $\mathrm{Co}^{2+}$ concentration in the entire potential range shown. This clearly shows the inhibitory effect of the $\mathrm{Co}^{2+}$ ions on the rest of the electrode processes, similarly to the impact of the less noble metal ions in other cases of anomalous codeposition. A comparison of the above mentioned curves also underpin that the sulfate ions do not have a significant role in the deposition kinetics since their concentrations were identical.

Figure 2.b shows the polarization data for the same solutions in a wide potential and current density range. The cathodic current increases monotonuously with the increasing cathodic poarisation. The order of the current densities in the high-current and low-current regimes are the same for Solutions 3 to 5 . For Solution 2, the slope of the polarization curve is higher than for the rest of the curves. This large current increase for Solution 2 can be seen in the current density range where the $\mathrm{Ru}$ content of the deposit becomes vanishingly small (see below).

The composition of the Co-Ru alloys deposited at room temperature as a function of the current density can be seen in Figure 3. The Ru content in the deposit increases as the $\mathrm{Ru}^{3+} / \mathrm{Co}^{2+}$ ratio in the electrolyte increases. No deposit with zero Co content could be obtained, whichever concentration ratio was applied.

\subsection{Composition of the deposits prepared at high temperature}

The cyclic voltammograms recorded at $50{ }^{\circ} \mathrm{C}$ were similar to those obtained at room temperature. At elevated temperatures, the slope of the curves increased and the peak corresponding to the dissolution of Co appeared at around $-0.2 \mathrm{~V}$ (not shown).

The composition of deposits prepared at $50{ }^{\circ} \mathrm{C}$ is shown in Figure 4. For electrolytes in which $c\left(\mathrm{Ru}^{3+}\right)<c\left(\mathrm{Co}^{2+}\right)$, the $\mathrm{Ru}$ content in the deposit increased. However, for the electrolyte with the 
highest $\mathrm{Ru}^{3+}$ concentration (Solution 5), the Co content increased as a result of the change in temperature.

\subsection{Deposit morphology}

It was observed that the morphology of the deposits is a function of the composition, while the electrolyte composition, the current density and the temperature are of minor importance only. A typical series of SEM images is shown in Figure 5.

At low current density, where the deposit contains a few percent of Co only ( 2 and 8 at.\%), the coating is discontinuous. The round-shaped voids in the thin deposit correspond to surface spots where the hydrogen bubbles prevent the formation of a continuous coating. As the current density increased and, consequently, the Co concentration in the deposit was higher, the pits from the surface gradually disappeared, and the continuous coating became decorated with small hemispherical grains (these can be seen as white circles in the pictures). At the highest Co content (60 at.\%), the coverage of the substrate surface was complete and the number of extra grains decreased, but at the same time the stress in the deposit led to fractures.

The morphological features of the deposits could not be related to any composition fluctuation. Figure 6 shows a sample whose surface is covered with hemispherical grains. Local composition analysis was carried out by EDX at the labeled spots of various surface features. The EDX spectra shown in the inset indicate that the intensity ratio of the Co and Ru lines are practically the same. The only difference detected in the spectra is related to the $\mathrm{Cu}$ line intensity. This is smaller when the area analyzed is confined to the hemispherical grain because the distance of the $\mathrm{Cu}$ substrate from the deposit surface is higher.

The change in the deposit morphology as a function of the current density is in accord with the composition and the current efficiency. As Ru-rich areas covered the surface at low current density, the evolution of the hydrogen became less hindered, and the deposition efficiency decreased. This is why the deposits with high Ru content were discontinuous even after a very long deposition time. As the Co content of the deposits increased, the current efficiency was large enough to achieve a continuous deposit.

The SEM pictures in Fig. 5 were all obtained for samples deposited at $50{ }^{\circ} \mathrm{C}$. A similar set of pictures was recorded for samples produced at room temperature. The main difference was that the individual grains on the basic deposit layer were a bit more dendritic at the lower temperature, and the hydrogen-induced defects in the deposit were of smaller size. 


\subsection{Structural study}

XRD measurements were carried out for a few samples. Due to the small thickness of the deposit layers, all diffractograms were dominated by the substrate peaks. The only part of the diffractograms that is related to the deposits can be found around the 101 and 100 reflection. Two typical diffractograms are shown in Figure 7. Instead of sharp diffraction lines, fairly wide peaks could be seen in the diffractograms (one of which overlaps with the substrate peak at $45.35^{\circ}$ ). While the small intensity of these peaks is related to the thin deposit, their large width can be related primarily to the nanocrystalline nature of the deposits. No peak related to the known phases of the ruthenium dioxide could be identified in any of the diffractograms, which is in accord with the low oxygen content as detected by EDX.

The center of the broad peaks is in a good agreement with the composition of the deposits as measured by the EDX. As the Ru content of the samples increased, the peaks were shifted toward the low-angle direction and approached the expected position of the Ru reflection. The expected line positions calculated with the average deposit composition and by using the Vegard's law is in good agreement with the center of the peaks found in the diffractograms.

\subsection{Magnetoresistance}

Two-pulse plating was also tested with the electrolyte of high $\mathrm{Co}^{2+}$ concentration (Solution 1) by using the $\mathrm{Si} / \mathrm{Cr} / \mathrm{Cu}$ substrate. A $3 \mathrm{~nm}$ thick Co-rich layer was deposited during a galvanostatic pulse at $-30 \mathrm{mAcm}^{-2}$, while a subsequent potentiostatic pulse was applied with $-665 \mathrm{mV}$ constant potential. This pulse sequence was repeated 50 to 100 times, keeping the total charge passed constant for all samples. The deposition potential in the potentiostatic pulse was optimized by using the current transient recorded in the potentiostatic pulse [23] so that no Co dissolution could take place. The nominal Ru layer thickness (i.e., that calculated with a current efficiency of $100 \%$ ) varied between $1.5 \mathrm{~nm}$ and $6.75 \mathrm{~nm}$. Although the nominal Co and Ru layer thicknesses were close to each other, the deposits exhibited a small Ru content (below 1.5 at.\%). The deposition efficiency in the potentiostatic pulse was determined from the composition data under the assumption that the Co-rich layer was deposited with 100\% current efficiency. The current efficiency in the potentiostatic pulse was obtained as 2 to $3 \%$. Therefore, the nominal layer thicknesses did not characterize the sample well, and a very small composition modulation (or a low level of alloying) could be achieved only instead of a true layering. 
Due to the high Co content of the samples and the percolation of the Co-rich zones, no GMR was observed. Instead, all pulse-plated samples showed anisotropic magnetoresistance (AMR), which is characteristic of bulk ferromagnetic metals. There was a small decrease in AMR with the increase in Ru content of the deposits. The AMR achieved in the present work $(0.3 \%)$ was of the same order of magnitude than that obtained in an earlier work for Co-Ru alloys with similar compositions $[15,16]$.

No magnetoresistance study was possible with the deposits obtained from the low metal concentration electrolytes (Solutions 2 through 5). When the Ru content of the samples achieved a certain level, the stress between the deposit and the $\mathrm{Si} / \mathrm{Cr} / \mathrm{Cu}$ substrate was so high that the metal layers were spontaneously peeled off from the Si wafer.

\section{Conclusions}

Codeposition of Co with $\mathrm{Ru}$ is an anomalous process because Co is codeposited at moderately negative potentials where its deposition as a pure metal is not possible.

The codeposition of Co and Ru cannot be described in the same manner as that of many metal pairs where one of the metals is more noble than the other (like $\mathrm{Cu}$ in $\mathrm{Ni}-\mathrm{Cu}$ or $\mathrm{Ag}$ in $\mathrm{Ag}$-Co alloys). Namely, in the latter cases the codeposition of the more noble metal can be described as a mass transfer limited process when the less noble metal is deposited at a high rate. Therefore, the composition of the deposits that can be achieved at high current density is regulated by the mass transfer of the precursor cations, and the molar fraction of the more noble metal never becomes zero, although it can be made very small. On the contrary, in the case of the Co-Ru pair, deposition at high current densities often leads to deposits with a vanishingly small Ru content, and the codeposition of Ru besides Co cannot be described as a mass transfer limited process. Apparently, the kinetics of the codeposition of Co and Ru is significantly different when a high $\mathrm{Ru}$ content and when a high Co content alloy is formed. Deposition of pure Ru was not possible with any $\mathrm{Co}^{2+}$ to $\mathrm{Ru}^{3+}$ concentration ratio tested.

No multilayer samples could be deposited with the conventional two-pulse plating method.

Besides the fact that pure Ru deposition was not feasible, the very low current efficiency during the low-current pulse also prevented us from obtaining a $\mathrm{Ru}$ (or at least a Ru-rich) layer.

The morphology of the Co-Ru deposits was determined by the Co content of the alloy. This latter parameter had a more decisive influence on the deposit morphology than the electrolyte composition or the current density. For high Ru content, the thickness of the deposit was limited, since the thin Ru-rich coating accelerated the hydrogen evolution, and further metal ion reduction 
was not possible. Continuous deposits could only be achieved in cases when the Co content in the deposit was sufficiently high (at least 40 at.\%). The XRD measurements indicated the formation of nanocrystalline alloys for Co-Ru alloys of 30 to 60 at.\% Ru contents.

\section{Acknowledgement}

Financial support of the Hungarian Scientific Research Fund (OTKA) through grant \# NN-79846 is acknowledged. The work of M. Jafari Fesharaki in Hungary was supported by a scholarship of the Iranian government.

\section{References}

[1] Cavallotti PL, Bestetti M, Franz S (2003) Electrochim Acta 48:3013-3020

[2] Wang F, Hosoiri K, Doi S, Okamoto N, Kuzushima T, Totsuka T, Watanabe T (2004) Electrochem Commun 6:1149-1152

[3] Zana I, Zangari G, Shamsuzzoha M (2005) J Magn Magn Mater 292:266-280

[4] Jeong GH,. Lee CH, Jang JH, Park NJ,. Suh SJ (2008) J Magn Magn Mater 320:2985-2987

[5] Cortés M, Gómez E, Vallés E (2010) Electrochem Commun 12:132-136

[6] Rožman KŽ, Kovač J, McGuiness PJ, Samardžija Z, Markoli B, Kobe S (2010) Thin Solid Films 518:1751-1755

[7] Huang Q, Bonhote C, Lam J, Romankiw LR (2007) ECS Transactions 3:61-69

[8] Yasin HM, Denuault G, Pletcher D (2009) J Electroanal Chem 633:327-332

[9] Safranek WH (1974) The Properties of Electrodeposited Metals and Alloys - A Handbook, American Elsevier Publishing, New York, Chapter 15, pp. 369-374

[10] Reid FH, Blake JC (1961) Trans Inst Met Fin 38:45-51

[11] Szabó S, Bakos I (1987) J Electroanal Chem 230:233-240

[12] Vuković M, Čukman D (1999) J Electroanal Chem 474:167-173

[13] Juzikis P, Gudavičiūtė L, Matulionis E (1995) Platinum Metals Rev 39:68-71

[14] Juzikis P, Gudavičiūtė L, Messmer A, Kittel MU (1997) J Appl Electrochem 27:991-994

[15] Bakonyi I, Tóth-Kádár E, Tóth J, Kiss LF, Pogány L, Cziráki Á, Ulhaq-Bouillet C, PierronBohnes V, Dinia A, Arnold B, Wetzig K (2002) Europhys Lett 58:408-414

[16] Bakonyi I, Tóth-Kádár E, Cziráki Á, Tóth J, Kiss LF, Ulhaq-Bouillet C, Pierron-Bohnes V, Dinia A, Arnold B, Wetzig K, Santiago P, Yacamáne MJ (2002) J Electrochem Soc 149:C469-C473 
[17] Parkin SSP (1991) Phys Rev Lett 67:3598-3601

[18] Parkin SSP, More N, Roche KP (1990) Phy Rev Lett 64:2304-2307

[19] Bloemen PH, Kesteren HW, Swagten HJM, de Jone WJM (1994) Phys Rev B 50:1350513514

[20] Zoll S, Dinia A, Jay JP, Meny C, Pan GZ, Michel A, El Chahal L, Pierron-Bohnes V, Panissod P, Van den Berg HAM (1998) Phys Rev B 57:4842-4848

[21] Massalski TB (Ed.) Binary Alloy Phase Diagrams, Second Edition Plus Updates on CDROM, ASM International, Materials Park, Ohio, USA, 1996.

[22] Zhu AL, Teo MY, Kulinich SA (2009) Appl Catal A 352:17-26

[23] Péter L, Liu QX, Kerner Z, Bakonyi I (2004) Electrochim Acta 49: 1513-1526

Table 1. Composition of the electrolytes. The $\mathrm{pH}$ value of all electrolytes was $1.5 \pm 0.1$.

\begin{tabular}{|c|c|c|c|c|c|c|}
\hline \multirow{2}{*}{ Electrolyte } & \multicolumn{5}{|c|}{ Component concentrations / mol dm ${ }^{-3}$} \\
\cline { 2 - 7 } & $\mathrm{RuCl}_{3}$ & $\mathrm{CoSO}_{4}$ & $\mathrm{MgSO}_{4}$ & $\mathrm{H}_{2} \mathrm{SO}_{4}$ & $\mathrm{KCl}$ & $\mathrm{H}_{3} \mathrm{BO}_{3}$ \\
\hline 1 & 0.020 & 1.0 & 0 & 0.001 & 0.25 & 0.25 \\
\hline 2 & 0.005 & 0.095 & 1.0 & 0 & 0.25 & 0.25 \\
\hline 3 & 0.020 & 0.080 & 1.0 & 0 & 0.25 & 0.25 \\
\hline 4 & 0.045 & 0.055 & 1.0 & 0 & 0.25 & 0.25 \\
\hline 5 & 0.060 & 0.040 & 1.0 & 0 & 0.25 & 0.25 \\
\hline
\end{tabular}




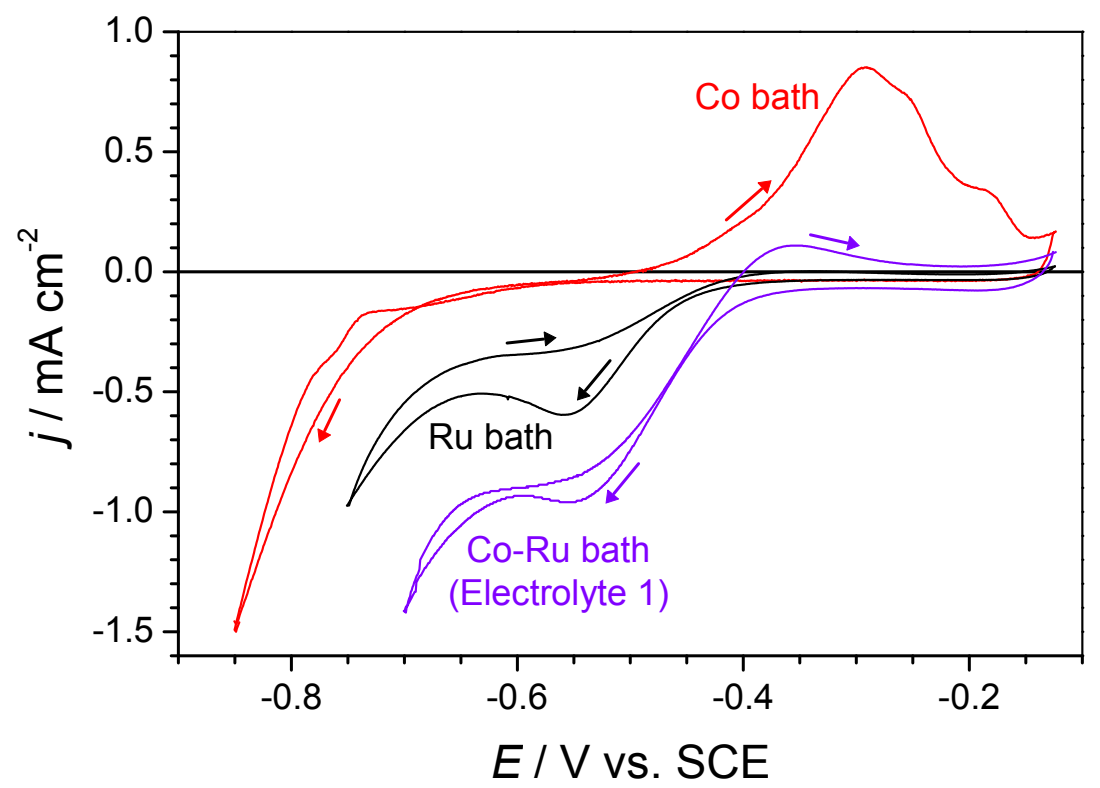

Figure 1 - Cyclic voltammetric curves obtained for Electrolyte 1, for a Ru-free bath where all other components and concentrations are identical to Electrolyte 1 and for a Co-free bath where $\mathrm{MgSO}_{4}$ replaced $\mathrm{CoSO}_{4}$ in Electrolyte 1 . Sweeps were recorded at a rate of $3 \mathrm{mV} \mathrm{s}^{-1}$ at ambient temperature. The figure shows the $2^{\text {nd }}$ continuous sweep obtained for a freshly-prepared $\mathrm{Cu}$ cathode. 

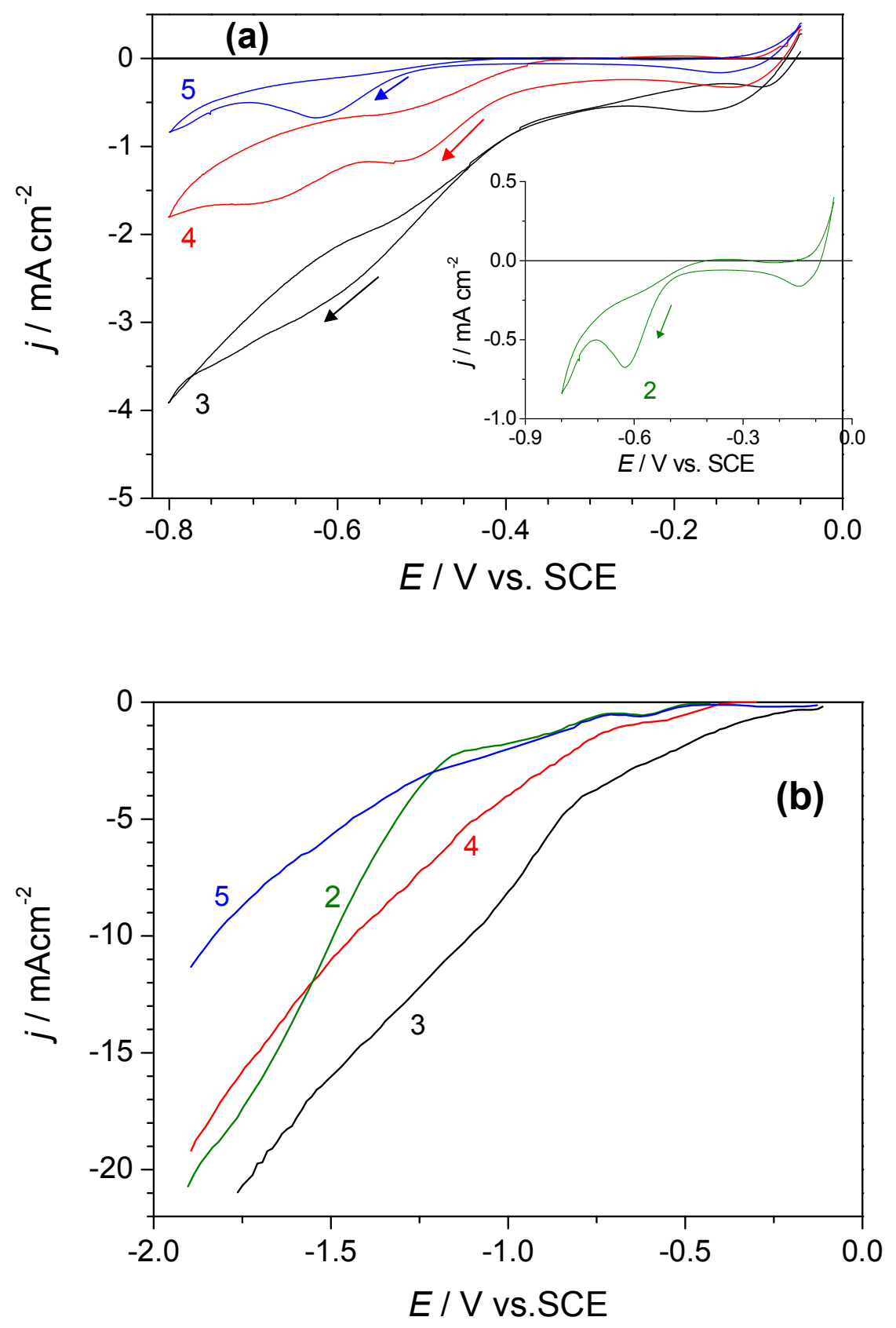

Figure 2 - (a) Cyclic voltammetric curves obteined for electrolytes with various $\mathrm{Co}^{2+} / \mathrm{Ru}^{3+}$ concentration ratios at room temperature. Numbers refer to the solutions as listed in Table 1. Sweep rate: $3 \mathrm{mV} \mathrm{s}^{-1}$. The figure shows the $2^{\text {nd }}$ continuous sweep obtained for a freshly-prepared $\mathrm{Cu}$ cathode. (b) Linear sweeps recorded in a wide potential range for the same electrolytes. 


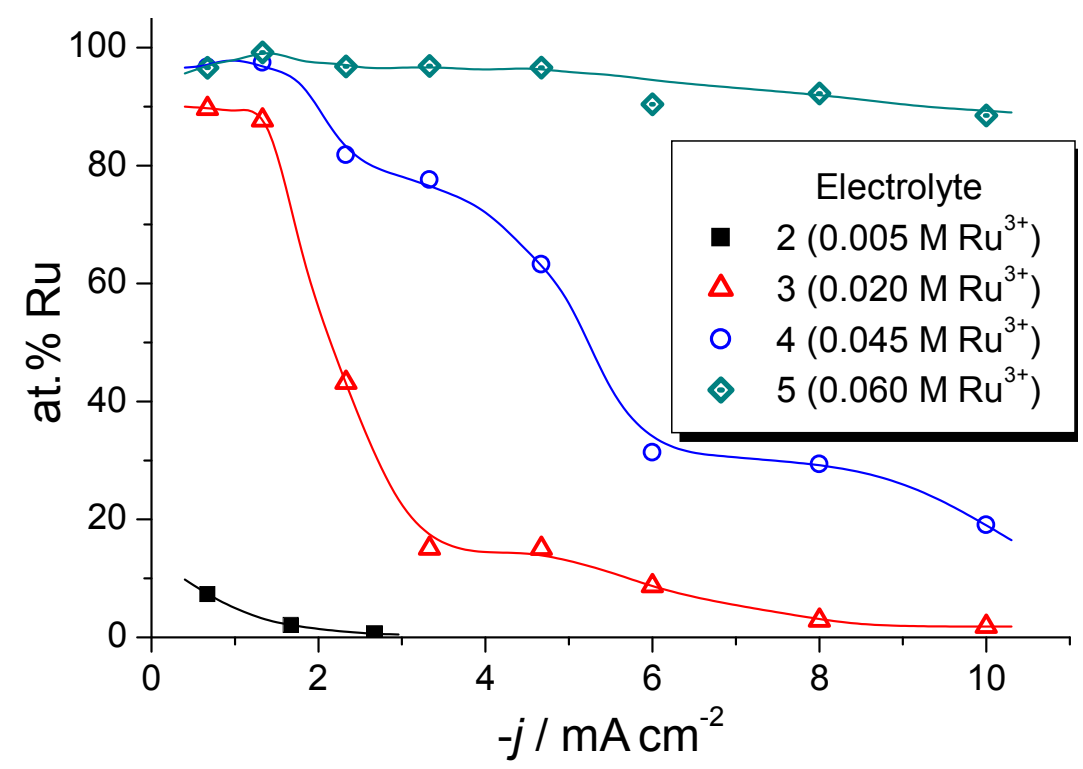

$\underline{\text { Figure } 3}$ - Composition of electrodeposited Co-Ru alloys obtained from electrolytes with reduced total metal concentration at room temperature. Lines serve as a guide for the eye only.

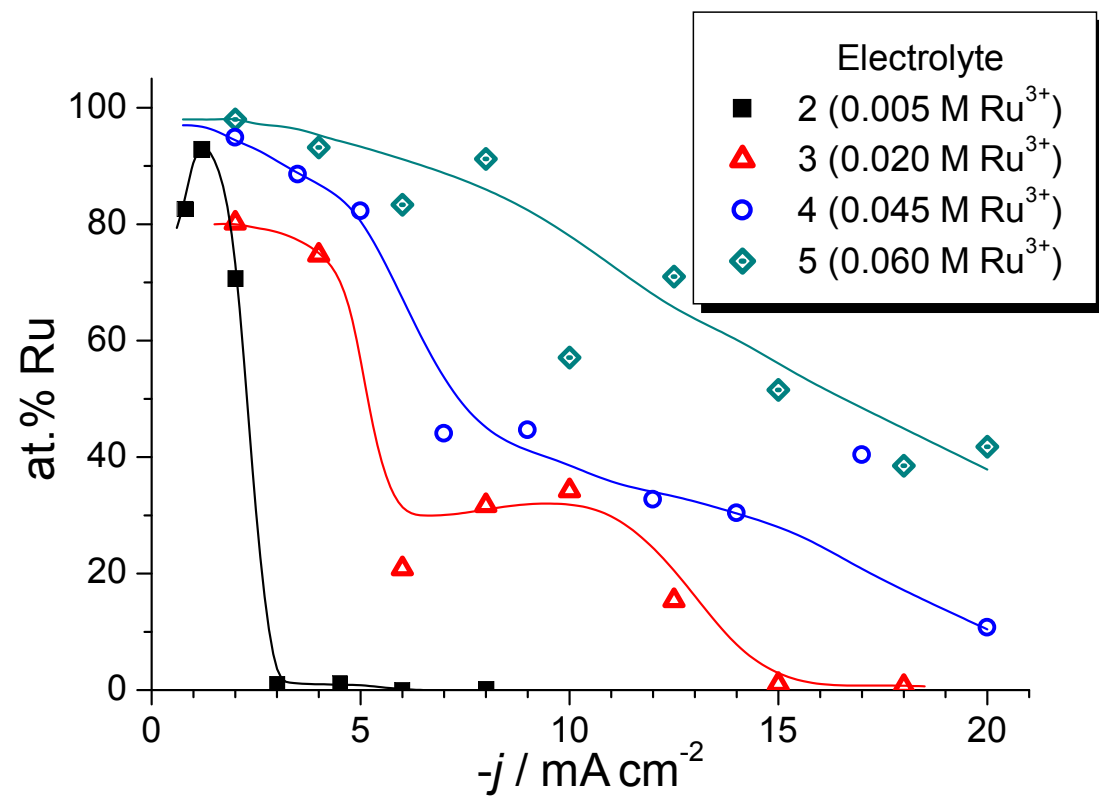

Figure 4 - Composition of electrodeposited Co-Ru alloys obtained from electrolytes with reduced total metal concentration at $50{ }^{\circ} \mathrm{C}$. Lines serve as a guide for the eye only. 

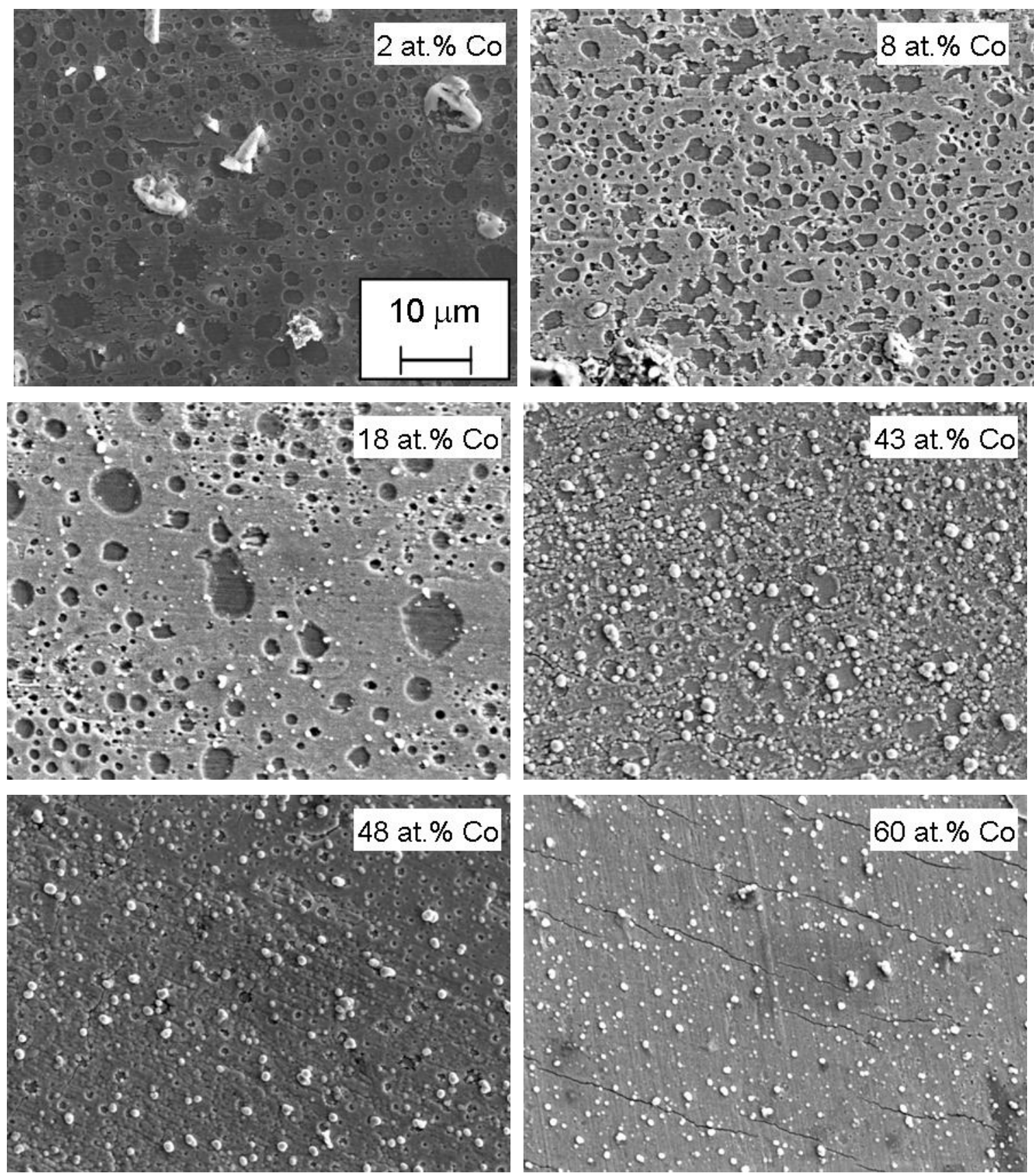

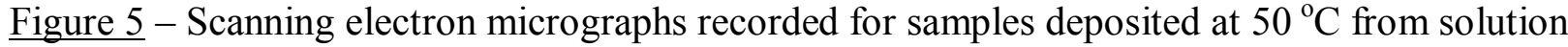
5 . 


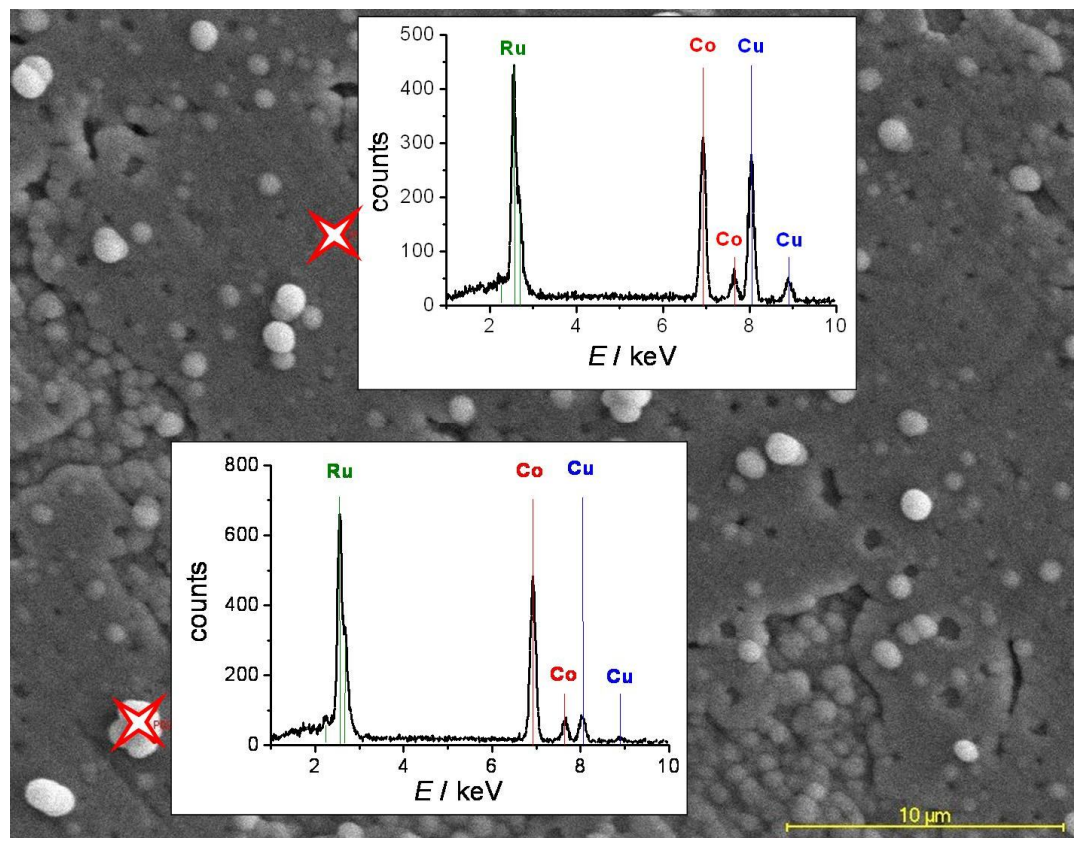

$\underline{\text { Figure } 6}$ - Scanning electron micrograph recorded for the sample deposited at $50{ }^{\circ} \mathrm{C}$ from solution 5 at a current density of $-15 \mathrm{mAcm}^{-2}$. Insets show the local analysis marked by a hollow cross at the left side of the EDX curves.

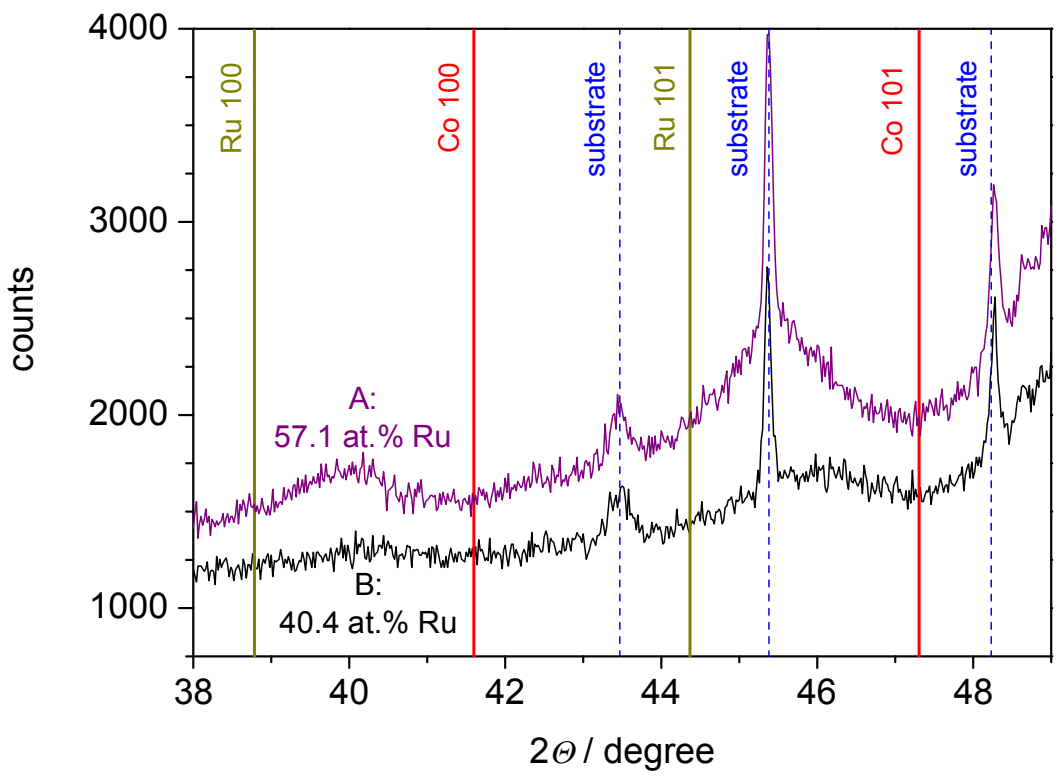

Figure $7-\mathrm{XRD}$ measurements obtained for samples with solution 5 at $50{ }^{\circ} \mathrm{C} . \mathrm{A}: j=-10 \mathrm{mAcm}^{-2}$; $\mathrm{B}: j=-25.2 \mathrm{mAcm}^{-2}$. Solid lines show the expected position of the diffraction peaks of the pure hcp Co and Ru metals. Dashed lines indicate the peaks related to the substrate. 